\title{
NORMAS MORALES Y NORMAS JURÍDICAS
}

a distinción práctica y teórica entre moral y derecho ha sido resuelta, en general, en términos ontológicos: es la moral, como cosa, que se diferencia del derecho, como cosa distinta. Por cierto que se trata de cosas nada simples y de difícil identificación. Pero, para esta actitud, que posiblemente corresponda a los presupuestos ontológicos tácitos de los lenguajes naturales y las comunicaciones establecidas en ese nivel, esas cosas o entes -la moral y el derecho- pueden ser datos de la más diversa índole, y sus diferencias ser también de muy diversa variedad. Pero, ateniéndose a la extrema vaguedad de aquellos presupuestos, las relaciones también supuestas entre el dominio objetivo denominado «moral» y el correlativo «derecho», son también muy diversas: por lo general se supone que alguna superposición (intersección) se da entre ambos dominios. En discursos más específicos de moralistas y juristas, la tendencia puede ser más radical: algunos pensadores moralistas consideran al derecho incluido en la moral, como un subconjunto propio o como equivalente. Algunos juristas positivistas piensan ambos dominios como excluyentes.

Ante la indefinición normal con que nos manejamos en los lenguajes naturales, las distinciones supuestas o propuestas entre moral y derecho pueden ser analizadas mejor intentando averiguar qué supone efectivamente el lenguaje técnico de los juristas, prácticos y teóricos, cuando aluden al problema de las relaciones entre la moral y el derecho. Pues los juristas tienden a pensar moral y derecho en términos normativos, poniendo de lado el problema bizantino de si en la experiencia social se dan hechos morales distintos de los fenómenos jurídicos, hechos y fenómenos que muchas veces son considerados datos empíricos constituídos por conductas humanas y otras cosas, y no simplemente por normas cuya caracterización empírica no es tan sencilla.

En dicho lenguaje, sin embargo, se dan corrientemente ciertas imprecisiones. Por de pronto, se supone que en el derecho 
ciertas normas, en función prescriptiva, desempeñan un papel esencial. Ello no es tan claro en lo que hace a la moral, donde no siempre es nítida la idea de norma moral, propia quizás solamente de aquellas morales denominadas prescriptivas. Hurgando un poco, cabe admitir que el jurista aceptaría que tanto derecho como moral son conjuntos normativos, aunque ambos conjuntos puedan contener otros elementos. Ello, esta diversa composición de los dominios, implica que el jurista presupone que el derecho no se identifica con la moral: un principio moral, por caso, integra la moral, pero no es necesariamente parte de un derecho positivo. Pero la concepción de moral y derecho, como códigos prescriptivos, también supone que en los mismos se dan normas, reglas o prescripciones de distinto nivel: la moral no sólo contiene reglas de conducta sino reglas que imponen condiciones necesarias para la validez valorativa de las normas de primer nivel y, quizás, principios más elevados aún que definen nociones supremas como la de bien, deber moral o virtud. En derecho, tenemos ciertamente normas que, en principio, parecen dirigirse a regular la creación y anulación de normas, a determinar los criterios mínimos de validez de las mismas y las pautas para su aplicación. La estructura, pues, de ambos conjuntos normativos no es idéntica, ni los conjuntos son homólogos.

Además, aunque de manera oscura, los juristas admiten alguna relación entre los códigos morales y los órdenes jurídicos, aunque ciertamente no indaguen precisamente cuál pueda ser específicamente la relación supuesta. No entraré aquí en esta cuestión, a la que he encarado en otros trabajos ${ }^{1}$, pero aludiré brevemente a la propuesta de suponer un conjunto normativo simultáneamente moral y jurídico, donde toda norma jurídica esté enlazada a una moral por ciertas precisas relaciones lógicas. Ello significa tanto como establecer vínculos necesarios y suficientes entre moral y derecho, pero ya no como relaciones entre dos conjuntos distintos.

A mí me gustaría suponer relaciones bastante laxas, como las que derivan de los siguientes axiomas débiles: 1) si algo es jurídicamente obligatorio, entonces está moralmente permitido (donde se establece un condicional material entre normas). Simbólicamente: (Ojp

> Pmp), donde la variable proposicional «p» representa cualquier estado de cosas normativamente modalizable

${ }^{1}$ Me refiero a Moral y derecho: sus relaciones lógicas, en Revista Jurídica de Buenos Aires, 1989-I, págs. 61-82. Cfr. tambiénSobre algunas relações logicas entre sistemas normativos juridicos e morais, en Revista Brasileira de Filosofia, vol. XXXVIII, fase. 155, 1989, págs. 238-252. 
y $\mathrm{O} j, \mathrm{O} m, \mathrm{P} j$ y $\mathrm{P} j$, las modalidades obligatorio y permitido, jurídica o moralmente respectivamente. Por su parte, 2) lo moralmente debido es jurídicamente permitido: (Omp $>$ Pjp). Se trata de enunciados indicativos, no de principios de segundo nivel; no dicen que lo jurídicamente obligatorio deba ser moralmente permitido. La lectura prescriptiva, con todo, refleja bien mis aspiraciones de un mundo práctico ideal, donde la autonomía moral de los sujetos quede resguardada y donde la validez del derecho no esté coartada por la ingerencia moralizante de nadie. Pues, si de resguardar la moral se trata, todo lo que se propone es que quien considera que algo está moralmente vedado, pueda jurídicamente omitir el acto cuestionado: quizás moleste a alguien una exhibición pública, como una película o un programa de televisión. Mientras nadie esté obligado jurídicamente a presenciar tales cosas, no parece que su dignidad moral se vea menoscabada, puesto que mantenerla dependerá exclusivamente de sus propios actos. De ahí, quizás, que los defensores a tales censuras, lejos de señalar que ellos evitan incurrir en los actos que condenan, invocan siempre supuestos menoscabos a entidades genéricas, como la cultura nacional o tradición patria que ellos ciertamente no representan (pues son entes carentes de representación) y que, en todo caso, no están dotados de personalidad moral alguna, en cuanto no están sujetos a prescripciones normativas de ningún tipo.

Las relaciones entre prohibiciones morales y jurídicas quedan establecidas en las consecuencias siguientes (donde el símbolo «N» representa la negación proporcional: los teoremas derivables $(\mathrm{NPjp}>\mathrm{PmNp})$ y $(\mathrm{NP} m p>\mathrm{P} j \mathrm{~Np})$ : está permitido moralmente no cumplir los actos jurídicamente vedados y el derecho permite omitir lo que está moralmente prohibido.

Cabe admitir, pues, deberes jurídicos que no implican obligación moral alguna. Las tesis excesivamente fuertes, que predican que toda norma jurídica deba tener fundamento moral $\mathrm{y}$, por ende, que aquéllas incompatibles con reglas morales quedan excluidas del derecho objetivo, no valen con respecto de los axiomas sugeridos. Por lo tanto, lo moralmente indiferente (P $m p$ \& NOmp), queda definido, por estos axiomas, como la permisión de omitir lo que no es jurídicamente obligatorio, pero indefinido en cuanto se trate de omitir lo jurídicamente prohibido, postura que, creo, satisfaría a los juristas. Las facultades o acciones libres jurídicas no son moralmente obligatorias -cabe no hacerlas-, pero la moral nada establece con respecto de la validez del cumplimiento de las obligaciones. El rigorista jurídico no es de por sí una persona moralmente virtuosa. Algunos 
moralistas -como los adherentes a la línea tradicional escolástica y al kantismo -admitirían esta postura, que permite ser moralmente virtuoso al no llevar a cabo actos jurídicamente permitidos pero moralmente condenados (como los pecados capitales, por ejemplo, que parecen moralmente repudiables, para ciertas morales, pero que normalmente los derechos objetivos autorizan). Sin embargo, los axiomas no autorizan a desobedecer sin más a las obligaciones jurídicas, que son prima facie moralmente válidas.

Estos axiomas son más débiles que los propuestos para formalizar sistemas mixtos, como los presupuestos, en el terreno del derecho, por el iusnaturalismo escolástico, o por escuelas que consideran que el derecho está esencialmente integrado por algunos valores morales, como el de justicia. En efecto, en parejos sistemas, tenemos axiomas mas enérgicos: $(\mathrm{O} j \mathrm{p}>\mathrm{O} m \mathrm{p}) \mathrm{y}(\mathrm{O} m \mathrm{p}>\mathrm{Pjp})$, que conducen a derivaciones problemáticas ${ }^{2}$. Por ejemplo, son teoremas derivables $(\mathrm{P} m \mathrm{p}$, $\mathrm{Pjp}$ ), todo lo moralmente permitido es jurídicamente permitido y su conversa, todo lo jurídicamente prohibido es moralmente prohibido $(\mathrm{Vjp}>\mathrm{Vmp}$ ), que suenan excesivos a los juristas quienes pueden traer a cuento numerosos contraejemplos. Por cierto que teoremas como [Om (Ojp > Omp)] [Oj (Ojp > $\mathrm{O} m \mathrm{p})$ ], que establecen que es moralmente obligatorio que lo que sea jurídicamente obligatorio lo sea también moralmente y que es deber jurídico que toda obligación jurídica obligue moralmente, suenan a absolutistas, política y moralmente. Los teoremas más débiles, diría yo, permiten un cierto liberalismo político esclarecido y un individualismo moral más amplio.

Pero el análisis formal de normas morales y jurídicas, en el lenguaje mixto, técnico a medias, de la jurisprudencia y de los moralistas teóricos, permite advertir que hay, a nivel sintáctico, diferencias más arraigadas entre enunciados normativos morales y normas jurídicas, diferencias que no siempre han sido suficientemente atendidas. Por de pronto, los juristas cuentan con ciertos esquemas relativos a la buena formación sintáctica de los enunciados normativos, reglas que pueden ser vistas como recursos recursivos para la definición de que entiendan por norma jurídica en su labor práctica y teórica. Tales reglas de formación

${ }^{2}$ Cfr. N. da Costa y L. Puga, Logica deõntica e direito, Boletim da Sociedade Paranaense de matematica, vol. 8. núm. 2, 1987, págs. 141-154; y N. da Costa, L. Puga, Logica, moral e direito, en actas VIII Simposio Latino-americano de lógica matemática, Universidad de Paraíba, 1989. 
no han sido propuestas por la ética analítica, ni serían consideradas como definiciones recursivas de regla moral.

En efecto, la teoría del derecho, con las normales variantes, propone esquemas canónicos para los enunciados reconocidos como normas jurídicas significativas. Por ejemplo, Kelsen propone que toda norma jurídica puede ser interpretada como un enunciado condicional cuyo consecuente está normativamente modalizado como debido (o con sus variantes deónticas), y que contiene, como variables sintácticamente necesarias, términos relativos a la acción de cierto sujeto o sujetos en determinado tiempo y lugar. Estas variables son diversamente cuantificables. Pero toda norma jurídica con sentido, esto es: sintácticamente bien formada, establecería que dados ciertos hechos antecedentes (cuyos criterios de verdad son dogmáticamente sentados), es debida (está deónticamente caracterizada) la acción de cierto sujeto en cierto lugar y tiempo. Los dominios de esas variables Kelsen los denomina Geltungsbereiche, ámbitos o dominios de la validez de la prescripción cuya modalidad expresa una función normativa (normative Funktion) ${ }^{3}$. Sin embargo, parece claro que estas reglas sintácticas de formación de las normas jurídicas son elementos del metalenguaje de la teoría del derecho y no momentos de una descripción inductiva de las normas positivas que la dogmática jurídica estudia. Propuesta semejante encontramos -con algunas variantes- en el análisis formal propuesto, por ejemplo, por G. von Wright ${ }^{4}$ y otros, de las normas jurídicas. Nada de semejante, en cambio, tenemos en la teoría ética con respecto de las normas morales.

Un precepto moral, como el «no mentir» o el «no matar» del Decálogo, parecen, al jurista, enunciados incompletos: ¿obligan acaso a todo sujeto en todo tiempo y lugar? O, casuísticamente, ¿cabe atribuirles ámbitos de validez personales más limitados, como efectivamente hacemos en nuestros juicios morales corrientes? Algunas personas, como el médico piadoso, pueden mentir frente al enfermo temeroso; en ocasiones de riesgos para terceros, podemos engañar al victimario que busca su víctima.

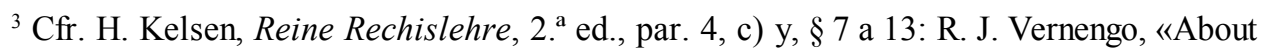
some fomation rules for legal lenguages», en Law, state and international order: essays in honor of H. Kelsen, University of Tennessee Press, 1964, págs. 229 y sigs.; y, R. Moore, Legal norms and legal science, Honolulu, 1978, University of Hawai Press, págs. 118 y, sigs. Con respecto a una moral normativa, cfr. H. Kelsen, Allgemeine Theorie der Normen, Viena. 1979, cap. 40.

${ }^{4}$ Cfr. G. von Wright, Norm and action, cap. VI. 
Sin embargo, algunos artificiosos dilemas morales han sido pergeñados a partir de esa insuficiencia sintáctica de los preceptos morales ${ }^{5}$. Si pretendemos que las reglas morales valgan universalmente -esto es, para todo sujeto y en toda ocasión-, ¿cómo justificar que podamos mentir sobre el paradero del perseguido político que sus eventuales torturadores buscan en mi casa? ¿Consideraríamos moralmente correcta la conducta de quien, por no incurrir en mentira, se hace cómplice de acciones horrendas? O, más frívolamente, ¿alguien calificaría de inmoral a quien incurre, como todos lo hacemos cotidianamente, en mentiras banales o piadosas por razones de pura convención social?

Pero de estas notorias diferencias sintácticas, que apuntan a reglas diferentes de formación de los enunciados normativos jurídicos o morales, cabe advertir, en los usos lingüísticos de los juristas, otras características interesantes. El tiempo, por ejemplo, juega funciones importantes en los enunciados jurídicos. No sólo en cuanto la determinación temporal sirve para identificar acciones y hechos, sino en cuanto los efectos del transcurso del tiempo pueden ser jurídicamente regulados. Por añadidura, como es sabido, algunas posibles formas de encarar las acciones jurídicamente reguladas y sus cambios es recurriendo a esquemas de lógicas temporales. Pero pensemos un caso más sencillo: los derechos positivos cuentan con una institución peculiar, la prescripción de obligaciones jurídicas. El deudor que debe pagar su deuda, queda liberado de ella con el transcurso del plazo de prescripción; el autor del delito no procesado dentro de un cierto lapso, queda exento de la aplicación de la pena, para señalar dos manidos efectos de la prescripción.

Cabría pensar ese efecto así: la acción que era obligatoria pasa a ser facultativa, la acción que estaba prohibida deja de serlo. Pero tal interpretación no parece correcta. Uno diría, quizás, que la norma que impone una obligación, puede tener un ámbito de validez limitado, a cuyo término entran a jugar otras normas. Quien se ha obligado contractualmente a cumplir una prestación, está obligado a hacerlo en un cierto tiempo; transcurrido el término de validez temporal, invocando la prescripción, el deudor puede manifestar, en el orden civil, que su obligación ha quedado derogada por una norma facultativa, incompatible con ella, si tal segunda norma de reemplazo o de clausura efectivamente existe en el derecho objetivo. En el orden penal, el juez obligado a sancionar, durante un cierto lapso, al autor de una

${ }^{5}$ Cfr. R. Routley y V. Plumwood, Moral dilemmas and the logic of deontic notions, Australian National University, 1984. 
acción ilícita, queda inhibido (esto es: le queda prohibido) aplicar una sanción. En ello consiste el juego de la prescripción de los delitos en los derechos penales liberales. No diríamos, por cierto, que la acción que suponemos prohibida a todo ciudadano de cometer un delito, está permitida en cuanto acción futura posterior a la prescripción. Con Kelsen, se sostendría que las normas penales no tienen como ámbito de validez personal a los autores de delitos, que son simplemente hechos antecedentes de las obligaciones sancionatorias de los jueces. La prescripción penal modifica las obligaciones de los jueces, y no los deberes corrientes de los ciudadanos.

En otros términos, el transcurso del tiempo como prescripción altera el carácter normativo con que ciertas acciones se encuentran reguladas en los derechos objetivos. Y ello vale, inclusive, frente a obligaciones que pretendemos, por buenas razones políticas, que son imprescriptibles. Los derechos humanos -se suele interpretar así los derechos que enumeran documentos como la Declaración internacional de derechos del hombre o ciertas garantías que contienen las constituciones modernas-, serían válidos en todo tiempo. Pero sucede, conforme a normas de igual rango, que ninguna persona, en principio, puede quedar sujeta a amenaza sancionatoria indefinida. Puede bien ser, por lo tanto, que pensemos que todo ser humano está obligado a respetar los derechos humanos de todo otro ser humano, pero que los órganos sancionatorios, de cuyo efectivo funcionamiento depende el control de aquellos derechos, estén inhibidos de sancionar a los violadores de los mismos, por haber transcurrido términos de prescripción o de perención procesal. De ahí que muchos autores, con el noble objetivo de preservar el prestigio de esos derechos y mantenerles una justificación normativa suficiente, propongan que se trata de derechos y obligaciones morales. Derechos y deberes morales que, según se dice oscuramente, son anteriores a los correspondientes derechos y deberes jurídicos.

Claro está que los derechos y deberes morales no perimen. El transcurso del tiempo no pareciera ser razón suficiente para el cambio del carácter deóntico moral de una acción. $\mathrm{O}$, si se quiere: las normas morales no especifican sus ámbitos temporales de validez, salvo que se pretenda que lo cuantifican universalmente, como válidas para todo tiempo. Es un sinsentido, por ejemplo, afirmar que uno está moralmente obligado a una cierta acción sólo durante un tiempo, convirtiéndose luego la acción en moralmente indiferente. No hay prescripción moral ni las reglas morales tienen validez temporal particular. Los caracteres normativos 
usados en reglas morales tienen más bien el sentido de expresar una valoración de la acción normada, valoración que se supone verdadera intemporalmente. Decir que está prohibido mentir quiere decir que es malo, moralmente y siempre y donde sea, hacer tal cosa; decir que es obligatorio amar al prójimo, quiere decir que es bueno en todo tiempo y lugar, practicar esa virtud moral. La bondad o maldad moral del acto ni siquiera es alterada por el olvido o el perdón posterior de los titulares de los supuestos derechos morales o de las víctimas de faltas morales. De ahí, que la moral nos parezca atemporal o, incluso, eterna, mientras el derecho siempre es histórico y contingente. La moral, por ello, no admite cambios, mientras que los órdenes jurídicos son claramente inestables y alterables. Sólo las acciones facultativas moralmente -esto es: ni prohibidas ni obligatorias- son imprecisas, pues no estaríamos dispuestos a asegurar el valor eterno neutro de una acción moralmente indiferente. Por ello, quizás, quienes las califican, como se solía decir, de adiáforas, esto es: sin valor, piensen que tales acciones indiferentes son ajenas a una regulación moral propiamente dicha.

En este esquema de interpretación de las modalidades deónticas en un código moral, la modalidad de las acciones supererogatorias queda también indefinido, pues éstas, para serlo, no pueden ser obligatorias ni tampoco indiferentes. Para que valga moralmente la acción heroica o la renuncia del santo se requiere, obviamente, que no se trate de cumplimientos de obligaciones ni que el heroísmo o el renunciamiento atañan a acciones inocuas. De ahí que la teoría moral proponga otra clasificación de las acciones morales y, pari passu, de las modalidades adecuadas de las normas morales ${ }^{6}$. Pero en derecho las cosas no son así. Aquello que es jurídicamente obligatorio no siempre es bueno o justo, ni lo prohibido es siempre malo. Más bien, los juristas tienden a pensar como lo más valioso a las acciones reguladas como facultativas, en cuanto son el campo del ejercicio autónomo de la libertad del sujeto. Adviértase que, en un lenguaje de valores, una acción jurídicamente obligatoria no siempre es moralmente valiosa, aunque en el sistema mixto que arriba se mencionó ello sería consecuencia necesaria de esta interpretación. Y ciertamente la bondad valorativa de una obligación moral para nada coincide con el carácter deóntico jurídico que le atribuye el sistema lógico mencionado: puedo estar moralmente obligado a amar al prójimo, pero nos parecería aberrante que ello constituyera una

${ }^{6}$ Cfr. J. S. Fishkin, Beyond subjetive morality: ethical reasoning and political philosophy, Yale University Press, 1984, cap. 2 y apéndice C. 
obligación jurídica. Puede ser excelente moralmente un acto audaz de heroísmo, que los reglamentos burocráticos de los ejércitos modernos prohíben expresamente. Y, sobre todo, el gran valor que los juristas atribuyen al terreno de sus facultades, en cuanto delimitan el campo de la libertad, parece contraponerse a la calificación neutra que la moral atribuye, por definición, a las acciones moralmente indiferentes.

El esquema condicional kelseniano de las normas jurídicas, análogo al que la inteligencia artificial emplea para formalizar preceptos jurídicos en cláusulas condicionales, tampoco pareciera ser corriente en los códigos morales prescriptivos, salvo en el sentido trivial de que podemos atribuirles, conforme a reglas de la lógica tradicional, como antecedentes monótonos, cualquier enunciado. Tal no es el caso en las normas jurídicas, en que la verificación empírica de los antecedentes normativos es razón suficiente de la validez del consecuente normativo: si el juez debe condenar jurídicamente al delincuente, es en razón de haber éste cometido un delito. Ese acto ilícito es jurídicamente calificado como desvalioso (o inicuo o antisocial), solamente si el acto valioso resultante del cumplimiento por el juez de su deber de sancionar se lleva a cabo o es posible. Pero el valor de la obligación judicial quedaría desvirtuado si no se hubiera producido el hecho delictual antecedente. Esta forma de pensar es, en general, ajena, al juicio moral. Que mentir sea malo no depende, para los códigos morales corrientes, de los hechos antecedentes de la mentira. Mentir en cosa mala de por sí, para casi todas las morales prescriptivas. Más bien, la moral ha tendido a condicionar el carácter normativo del acto por sus consecuencias, como en el utilitarismo clásico, y no por sus causas antecedentes. Sea como fuere la explicación de estas diferencias, parece claro que, en el lenguaje técnico de la jurisprudencia, las normas del derecho positivo son traducidas a formas canónicas que, en todo cálculo lógico corriente, tienen consecuencias distintas que las normas categóricas de los códigos morales.

Vale decir: moral y derecho difieren, ya no sólo por la forma canónica de sus prescripciones, sino por las consecuencias lógicas que de tales formas son inferibles. Pero si consideramos que el significado de un enunciado cualquiera está delimitado, o se identifica, con el conjunto de sus consecuencias, resulta que normas morales y jurídicas, superficialmente homólogas, dicen y significan cosas distintas. $\mathrm{O}$, si se quiere, entre el «no matar» del Decálogo y el enunciado jurídico incompleto que prescribe también no matar, no puede encontrarse, en principio, ni equivalencia ni equipolencia. 
Es frecuente, en la literatura reciente, sostener también que en el razonamiento jurídico decisorio, como el que practican los jueces en sus fallos, y los juristas en los casos que teóricamente resuelven, la propiedad de monotonía no sería respetada. Es decir, se pretende -tema que requiere un análisis más minucioso- que el agregado de una tesis verdadera nueva, en los antecedentes de una norma que prescribe una cierta acción, puede privar de validez a la conclusión lógicamente válida obtenible con los antecedentes anteriores. Ello implicaría, como se ha sugerido últimamente, que la derivación argumentativa jurídica es no monotónica desde un punto de vista lógico ${ }^{7}$. No creo que tal cosa esté suficientemente fundada, y que la lógica del razonamiento jurídico requiera apartarse de las características clásicas de la noción de consecuencia deductiva. Pero, sea ello como fuere, lo cierto es que en el juicio moral tal cosa no ha sido ni siquiera insinuada: las prescripciones morales, que algunos moralistas clásicos, consideran enunciados dotados de valor de verdad, pueden ser premisas de inferencias tradicionales. Es bien sabido, que eminentes juristas, como Kelsen, o lógicos, como von Wright, niegan rotundamente que las normas jurídicas, en su función propia prescriptiva, cuenten con valor de verdad y puedan ser eslabones de procesos deductivos clásicos.

O bien, sea a priori o a posterori, se postula que el razonamiento jurídico -esto es: las inferencias con normas jurídicas está sujeto a lógicas divergentes específicas. La lógica deóntica standard, como la propuesta por von Wright, Hanson y la literatura clásica de esta segunda mitad del siglo, considera que la misma es una extensión modal de cálculos formales que respetan las características tradicionales de la deducción clásica. Otras lógicas, en cambio, como las lógicas deónticas paraconsistentes elaboradas en la última década, se apartan de esos cánones. O, en el afán de atenerse a la reconstrucción veraz de los procedimientos inferenciales que efectivamente los juristas llevan a cabo, se proponen lógicas normativas emparentadas con lógicas relevantes o naturales en las cuales recursos inferenciales clásicos dejan de tener validez ${ }^{8}$.

${ }^{7}$ Sobre el tema del razonamiento jurídico no monotónico, cfr. M. Smith, The formalization of legal reasoning, en Preproceedings of the III International Conference on «Logica, informatica e diritto», Florencia, 1989, págs. 693 y sigs.

${ }^{8}$ Sobre las lógicas adecuadas para el razonamiento jurídico, cfr., como ejemplo, F. Miró Quesada, Lógica jurídica idiomática, en Conferencias III Congresso Brasileiro de Filosofía do Direito, Paraíba, 1988, págs. 224 y sigs. 
Es difícil hoy formarse una opinión suficiente sobre estas cuestiones. Pues las mismas no sólo ponen sobre el tapete problemas relativos al alcance de los cálculos lógicos que presuntamente los juristas emplean, pero que los computadores requieren utilizar rigurosamente, sino que la idea misma de racionalidad lógica se vuelve insólita. ¿Acaso, como en algunos de los trabajos a que me refiero, la validez de un sistema formal sea puramente pragmática y la lógica válida para el derecho sea el sistema resultante de una logica utens reconstruido ex post facto? ¿Tiene sentido pensar una logica utens jurídica, que, por definición, es ad hoc? La noción recibida de racionalidad es dependiente de la creencia en la validez absoluta de una logica magna. Si en cambio, la racionalidad lógica de una inferencia jurídica dependiera de su correspondencia con los esquemas deductivos que, a posteriori, se hubieran obtenido del análisis de la misma inferencia, el razonamiento jurídico sólo alcanzaría una racionalidad relativa, cuando no redondamente circular, para decirlo redundantemente?

Frente a estos planteos, queda claro que las relaciones que se postulen entre normas jurídicas y normas morales tienen muchos presupuestos lógicos, en sentido lato, que hacen muy problemática la verdad de las tesis corrientes al respecto. Por ejemplo, ¿qué quiere decirse, en rigor, cuando se afirma, a partir de la filosofía o ideología que sea, que una norma jurídica se funda, o debe fundarse, en una norma moral o en un principio moral superior? La relación de fundamento, entre normas, pareciera que tuviera que ser entendida lógicamente, pues ciertamente no se trata de una relación de tipo empírico, como si se tratara de verificar que la efectividad de una norma jurídica puede ser incrementada de hecho invocando normas morales. En una posición extrema, pudiera pensarse que una norma jurídica tiene

También, para hacerse cargo de la variedad de lógicas requeridas para una adecuada formalización de inferencias jurídicas, cfr. L. E. Allen \& C. S, Saxon, Analysis of the logical structure of legal rules, en A. A. Martino \& F. Socci Natali (eds.), Automated analysis of legal texts, Amsterdam, 1986. págs. 385 y sigs.

${ }^{9}$ Sobre la relatividad de la lógica, cfr. J. von Heijenhoort, Absolutismo y relativismo en lógica, Universidad Autónoma de Puebla, Tercer Coloquio Nacional de Filosofía, Puebla, 1979; N. de Costa, Ensaio sobre os fundamentos da logica, Universidade de São Paulo, 1980, caps. 1, par. 5 y, 6 III, par. 5: J. Ladrière, Logique et argumentation, en De la métaphysique à la réthorique (ed. E. Meyer), Université de Bruxelles, 1986, págs. 23 y, sigs.: P. Gärdenfors. On the interpretation of deontic logic, en Logique et analyse, 21, págs. 371 y sigs. 
fundamento moral cuando se identifica con una regla moral; tal es, supongo, la creencia sustentada por quienes consideran que el derecho es un subconjunto propio de la moral, que el derecho se encuentra en relación subalterna con la moral. Pero esta identificación -las normas jurídicas fundadas moralmente son elementos del conjunto incluyente moral $\mathrm{y}$, en cuanto tales, miembros del subconjunto jurídico -pasa por alto la dificultad arriba señalada de que, en la comprensión corriente de los juristas, las normas jurídicas se expresan mediante enunciados normativos de estructura bien diferente del esquema sintáctico que se atribuye a las normas morales, diferencia reflejada, en la literatura clásica, en la distinción kantiana entre imperativos categóricos e hipotéticos ${ }^{10}$, o en la distinción sugerida por von Wright entre ideal rules que determinan el concepto de bondad de una cosa y technical norms o directivas ${ }^{11}$. Las reglas ideales y los imperativos morales categóricos establecen, como dice Kant, modelos conceptuales arquetípicos de conducta o, si se quiere, definiciones conceptuales de ideales morales. Estos enunciados morales tienen, como reconoce von Wright, «complicadas afinidades lógicas con los otros tipos principales de normas y con las nociones valorativas de lo bueno y lo malo» ${ }^{12}$. En cuanto tales, si bien no constituyen inmediatamente prescripciones motivadoras de conducta, son enunciados con características normativas. En cuanto tales, la lógica deóntica standard que normalmente se les atribuye corresponde, como señalaran R. Routley y B. Hanson, a un esquema de decisión que presupone un mundo ideal posible accesible: que algo sea obligatorio, para ese modelo presupuesto, significa que es verdad que todas las obligaciones se cumplen en todos los mundos posibles accesibles ${ }^{13}$.

${ }^{10}$ I. Kant, Kritik der praktischen Venunft, 37 y 52.

${ }^{11}$ G. von Wright, Norm and action, Routledge \& Kegan Paul, Londres, 1963. cap. 1, §7 a 10.

${ }^{12} \mathrm{Op}$. cit., pág. 13. Por cierto que von Wright distingue luego, desde un punto de vista formal normas (prescriptions) jurídicas categóricas e hipotéticas: ibídem, págs. 74-75.

${ }^{13}$ R. Routley y V. Plumwood, op. cit. supra nota 5, págs. 36 y sigs.: «But being beyond such deontic rules does not imply, being beyond rational procedures, indeed procedures that may be represented by way, of rules (though not controlled by deontie rules). The rational procedurs in question are essentially those of decision theory», y, la distinción entre «maximizing and satisizing procedures»: «maximizers will of course argue that it would he irrational to select anything but the best among the alternatives». B. Hanson, The dependency of deontic logic upon the general theory of decision, donde se señala que la semántica de los operadores deónticos de obligación y de permisión está estrechamente relacionada con la teoría de la decisión. La noción de obligación es 
Las normas jurídicas se asemejan, por un lado, a reglas técnicas o, textualmente en Kant, a imperativos hipotéticos. Sólo que si tales prescripciones condicionales son pensadas como premisas o conclusiones de inferencias deónticas standard, quedan automáticamente asimiladas a principios morales, a prescripciones que definen ideales éticos. Y, de ese modo, cabe identificarlas con preceptos morales, como sucede en la teoría clásica que ve a las normas jurídicas enunciados subalternos de preceptos morales. Ello ciertamente no corresponde a los usos que los juristas hacen en sus discursos prácticos de las normas jurídicas positivas, donde los recursos lógicos tienen un importante valor retórico en las argumentaciones y conclusiones litigiosas.

En otros términos, pensar que las normas jurídicas tienen un fundamento moral en cuanto se supone que son inferibles de reglas morales, lleva a sujetar al razonamiento jurídico a una lógica adecuada para extraer consecuencias de principios morales ideales. Se trata de una estrategia de máxima para racionalizar un contingente derecho histórico. De ahí que Kelsen haya visto en el derecho natural clásico, que subordina el derecho a la moral, un proyecto político de justificación a priori de cualquier derecho positivo.

Pero la relación de fundamentación entre moral y derecho suele ser vista, contemporáneamente, en términos distintos que en el iusnaturalismo clásico. Tenemos, para citar dos doctrinas actualmente vigentes, por un lado la tesis de que los principios morales son anteriores o previos a las reglas jurídicas, sin que esa prioridad temporal implique suponer una causalidad fáctica. No se trata de que las normas jurídicas adquieran existencia como consecuencia de la instauración previa de normas morales, pues éstas justamente no tienen fecha de creación alguna, sino que valen desde siempre. Las normas jurídicas, en cambio, como es notorio, son estatuidas por actos históricos de legisladores de carne y hueso. Si las normas jurídicas derivaran su existencia o validez normativa de normas morales preexistentes desde siempre, las normas jurídicas también serían eternas, lo que contradice la nota de positividad con que los juristas las caracterizan y haría redundante la mención de su ámbito temporal de validez.

semánticamente interpretada como si es verdad que todas las obligaciones se cumplen en un mundo moralmente ideal accesible: $y$, «the pursuit of the ideal world now obviously amounts to the application of the maximax rule:... since prevalent deontic logic corresponds to the maximax rule, there can be no reason to prefer the axioms of prevalente deontic logic to other axiomes sets corresponding to other decision rules» (la cita es de la pág. 80 ). 
Sin embargo, esta forma de hablar es frecuente en la literatura reciente sobre derechos humanos, a los que se atribuye una existencia previa a su promulgación jurídica, como derechos morales ${ }^{14}$. Si las normas morales no tienen validez temporal alguna, pues valen eternamente o para todo tiempo, no tiene mucho sentido situarlas como temporalmente anteriores a normas jurídicas positivas cuya «locación temporal», como dice von Wright, es bien particular.

La segunda manera de pensar la relación de fundamentación moral de las normas jurídicas que encontramos en la literatura reciente consiste en distinguir aquellas normas jurídicas que sí tienen ese fundamento. Las mismas no serían simplemente válidas, como se preocupan por averiguar los juristas, sino también legítimas. Esta propiedad es definida como «la concordancia de los principios sustentados por la regla de reconocimiento del sistema (jurídico) con los de la moral crítica o ética» ${ }^{15}$. Esta definición por cierto está ligada a la manera de concebir la regla de reconocimiento, sobre cuya naturaleza lógica cabe discrepar, pues quizás no sea una norma integrante de los órdenes jurídicos positivos, sino un enunciado del metalenguaje con que juristas y aún órganos decisorios analizan el derecho que estudian o aplican. En todo caso, la noción de legitimidad es relacionada con pautas valorativas morales y diferenciada de la noción de legalidad, con que Kelsen, por ejemplo, delimitaba la noción de fundamentación de la validez de las normas jurídicas.

La imprecisión lógica que he apuntado lleva a que, curiosamente, el tema de la legitimidad moral de las normas jurídicas aparezca invertido. Se trata ahora de saber si cabe legitimidad

${ }^{14}$ Cfr. por ejemplo, E. Fernández, Teoría de la justicia y derechos humanos, Ed. Debate, Madrid, 1984, pág. 106, donde se dice que «el origen y fundamento» de los derechos humanos, «nunca puede ser jurídico» (esto es: resultante de una norma promulgada positivamente), sino «previo a lo jurídico», pues «el derecho (me refiero -dice el autor- al derecho positivo) no crea los derechos humanos». El derecho positivo, resultado de acciones legisferantes, «reconoce» esas «exigencias éticas» previas y necesarias, convirtiéndolas en normas jurídicas. Sin embargo, el mismo autor, pocas páginas adelante, sostiene que «a cada derecho humano como derecho moral le corresponde paralelamente un derecho en el sentido estrictamente jurídico del término» (ibídem, pág. 109), donde la relación de fundamentación pareciera ser la de equivalencia señalada arriba. Cfr. la reiteración de estas posiciones en el ensayo de E. Fernández en J. Muguerza y otros, El fundamento de los derechos humanos, Ed. Debate, Madrid, 1989, págs. 155 y sigs. Se trata, sin duda, de una forma diluida, por decir así, de tesis viejas del iusnaturalismo, como el propio Fernández, con salvedades, admite (cfr. el último trabajo mencionado, págs. 157-8).

${ }^{15}$ Cfr. E. Garzón Valdés, Sobre el terrorismo de estado, en prensa, 1989. 
moral sin legalidad. Algunos autores señalan no sólo que «la moral desde los comienzos de la teorización presenta un carácter juridizado», sino que, frente al carácter legalizado de la vida social en general «el rol de la moral como hecho autónomo ha de estimarse como más bien exiguo: el sistema jurídico seguiría en pie, aun cuando la moral cayese en decadencia ${ }^{16}$. Un punto de vista semejante pareciera darse en autores très à la page, voceros de una novedosa ética discursiva, como J. Habermas: la legitimidad moral resulta ahora condicionada por la legalidad, aunque el problema siga siendo siempre el de las relaciones entre moral y derecho, relaciones cuyas definiciones permanecen en el terreno de las metáforas sugestivas. Sostiene Habermas que el derecho «exteriorizado» y la moral «interiorizada» se complementan mutuamente, relación un tanto vaga que es oscurecida un tanto más declarando que «más que esta relación de complementariedad nos interesa el simultáneo entrelazamiento de derecho y moral. Este se produce porque en el estado de derecho se hace uso del derecho positivo como medio para distribuir cargas de argumentación e institucionalizar vías de fundamentación y justificación, que se hallan abiertas en dirección a argumentaciones morales. La moral ya no flota sobre el derecho (como todavía sugiere la construcción del derecho natural racional) como un conjunto suprapositivo de normas. Emigra al interior del derecho positivo, pero sin agotarse en derecho positivo» ${ }^{17}$. Estas líneas enigmáticas quizás valgan un comentario estilístico: normas morales que «flotan» y que «emigran» al derecho para «enfrentarlo», por un lado, y «complementarlo» o «controlarlo» por el otro -como afirma el autor citado-, nada dicen de preciso sobre cuáles sean las relaciones que se postulan entre derecho y moral, mientras que permiten asumir que no se está muy en claro sobre qué sean la moral y el derecho de los que se predican relaciones incompatibles.

En Habermas esta moral que ha dejado de flotar sobre el derecho (esto es, supongo, que no lo incluye), pero que sí lo complementa y lo controla (aunque también resulta que el derecho complementa y controla a la moral) no es, sin embargo,

${ }^{16}$ Cfr., por ejemplo, J. M. Broekman, La separación entre derecho y moral: una estrategia del discurso jurídico, en Boletín de la Asociación Argentina de Filosofía del Derecho, núm. 28, La Plata, 1985, pág. 2.

${ }^{17}$ Cfr. al respecto, J. Habermas, Wie ist Legitimität durch Legalität möglich? Erste Vorlesung über Recht und Moral, en Kritische Justiz, I: cito la traducción: ¿Cómo es posible la legitimidad por vía de legalidad?, en Doxa 5. Cuadernos de Filosofía del Derecho, Universidad de Alicante, 1988, pág. 21 y sigs. El texto transcrito figura en la pág. 42. 
prescriptiva. La moral «atada al derecho mismo» sería de «naturaleza puramente procedimental» y se ha «desembarazado de todo contenido normativo determinado». Sólo con ese aspecto insólito, «un derecho procedimental y una moral procedimentalizada pueden controlarse mutuamente», afirma nuestro autor. Es quizás imposible entender qué tipo de relación precisa considera Habermas al describir de tal modo la complementariedad y control mutuo de derecho y moral. Quizás el derecho procedimental y la moral procedimentalizada sean el conjunto definido por la intersección del derecho y la moral, a saber el conjunto formado por la intersección del subconjunto jurídico integrado por normas procesales y del subconjunto moral integrada por aquellas normas procesales morales que Habermas supone contienen las morales prescriptivas. Se trataría de un subconjunto propio de la moral en que ésta «se ha desembarazado de todo contenido normativo determinado y ha quedado sublimada en un procedimiento de fundamentación de contenidos normativos posibles». Esto hace pensar, que esta moral formal (sin contenidos prescriptivos) y sublimada en «procedimientos de fundamentación» es, más bien, el conjunto de reglas metaéticas que determinan la validez («fundamentación») de las normas morales sustantivas. En cuyo caso, se advierte, sí, que la moral así delimitada controla el derecho: es, en terminología oscura, la antigua función que se atribuye a la moral como patrón (Maßstab) de la validez «absoluta» de los derechos positivos, que Kelsen analizara y descartara. Sólo que ahora la moral, que ya no «flota» sobre el derecho, pues se encuentra en otro nivel lingüístico, queda convertida en un «procedimiento de fundamentación» de las normas jurídicas posibles. Pero como esos procedimientos de fundamentación morales integran el conjunto que intersecta con el derecho, resulta que esos procedimientos son también, por definición, jurídicos. De ahí que Habermas sostenga que moral y derecho, en esta concepción, se «controlen mutuamente»y se encuentren ligadas «procedimentalmente» en un «simultáneo entrelazamiento de derecho y moral». De este abrazo, empero, la moral sale malparada, pues, debe requerir del derecho que «compense las debilidades de una moral autónoma», dándole suficiente obligatoriedad, característica que sólo puede adquirir -cree nuestro autor- mediante «su acoplamiento con el poder de sanción estatal» y su institucionalización jurídica ${ }^{18}$.

${ }^{18}$ En el texto de Habermas que comento -cuya versión definitiva seguramente ofrecerá variantes-, el derecho, sin embargo, tiene un papel predominante, pues a él le incumbe, en los estados de derecho, «distribuir cargas de 
Se comprende, entonces, muy bien que legitimidad moral y legalidad jurídica se compliquen, pues, en rigor, se trata de las mismas normas: las normas que, en el conjunto constituido por moral y derecho, regulan los procedimientos de «fundamentación y de justificación» de las normas sustantivas jurídicas y morales. Sea ello como fuere, Habermas considera que ese subconjunto de las normas morales que regulan los procedimientos de fundamentación de las propias normas morales y de las jurídicas, procedimientos que constituyen la argumentación moral, «queda institucionalizada como un procedimiento abierto, que obedece a su propia lógica y controla su propia racionalidad» ${ }^{19}$. Cuál es esa lógica propia de la moral -una lógica que definiría la racionalidad de los códigos morales y jurídicos- no nos es revelado por el momento, por lo cual mucho no cabe cuestionarla. La propuesta me parece similar a las lógicas propias de lo jurídico que hace años Cossio, por ejemplo, propiciaba, sin lograr formular un axioma, una regla de inferencia o un teorema ${ }^{20}$. Ante esta indefinición -no sabemos cuál sea la lógica propia de la moral procedimentalmucho sentido no tiene pretender que sea esa moral discursiva la que otorgue validez a las normas del derecho positivo o establezca los criterios de «legitimidad normativa» ${ }^{21}$. Aunque sabemos que dicha lógica, necesaria para la fundamentación ética de los enunciados jurídicos, no autorizaría derivaciones de fundamentación deductivas, aunque sí universalización y verdad de los enunciados morales. La verdad moral no sería, pues, hereditaria a través de la deducción lógica normal, sino pragmáticamente a través de instancias de esa prometida

argumentación e institucionalizar vías de fundamentación y, justificación» (op. cit. en nota anterior, pág. 42). Y no sólo eso, la noción de deber u obligatoriedad, tradicionalmente pensada como moral, queda localizada primariamente en el derecho: «Como de las convicciones morales no cabe esperar que cobren para todos los sujetos una obligatoriedad que en todos los casos las haga efectivas en la práctica, la observancia de tales normas sólo es exigible... si cobran obligatoriedad jurídica» (ibídem, pág. 41). Si entiendo bien, pues, las normas morales sólo obligan si son jurídicas. Y, consecuentemente, una norma jurídica es legítima (moralmente justificada) solamente si es válida legalmente. La tesis de Habermas se asemeja, pese al sesgo procesal, al positivismo ideológico que Bobbio caracterizara.

${ }^{19}$ Ibídem, pág. 43.

${ }^{20} \mathrm{Cfr}$. al respecto, R. J. Vernengo, Lógicas e ideologías, en Revista del Notariado, Buenos Aires, núm. 747, 1976, pág. 7, y, la versión corregida, Ideologías, lógicas y lógicas de la acción, en M. H. Otero (cd.). Ideologías y ciencias sociales, UNAM, México, 1979, págs. 199-213.

${ }^{21} \mathrm{~K}$. Tuori, Ética discursiva y legitimidad del derecho, en el mismo número de Doxa, Alicante, 1988, pág. 50. 
lógica del discurso práctico, a través de las acciones comunicativas. No se entiende por qué esas actividades, que no son inferencias lógicas, produzcan un efecto similar a la transmisión de una propiedad característica que la deducción cumple.

Me temo que esta pretensión de fundamentación del derecho, si bien no es comparable a las tesis moralizantes del iusnaturalismo clásico, incurre en irracionalidad. Pues no basta, para salvaguardarla, pretender que están en juego lógicas inéditas que excluyen procesos deductivos, ni que exista, por pura definición, una razón práctica en los trámites comunicativos entre los hombres, razón que sólo cabría postular metafísicamente en esas actividades, pero no definir formalmente. Y ello, tanto más, cuando esa lógica meramente supuesta no garantiza la verdad del juicio moral; éste es relativo al asentimiento o consentimiento del grupo social de que se trate. La ética discursiva, señala Cortina, «ha de reconocer la falibilidad de todos los conocimientos morales, como reconoce Habermas, y afirmar con caracteres de universalidad y necesidad únicamente las implicaciones morales de los presupuestos pragmáticos de la argumentación, pero la idea de un juicio moral que, no sólo se sabe siempre falible, sino que acepta como criterio de lo correcto lo que una

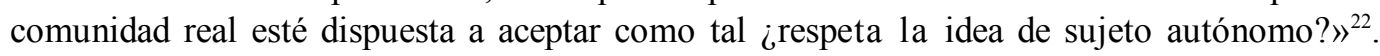
Más bien, cabe pensar, conforme al ingrediente lógico que siempre la idea de racionalidad ha contenido, que sólo algunos discursos sociales son racionales conforme a las reglas de consecuencia lógica que se asuman. Y corresponde no sorprenderse de que se haya tendido, en el kantismo, por ejemplo, a «hacer de la moral una forma peculiar, cuando no deficiente, de derecho», por la sencilla razón de que, en derecho, siempre se ha aceptado una racionalidad lógica y aún sistemática, frente a morales intuicionistas cuando no meramente voluntaristas, como las que recurren a intuiciones emocionales de valores o a fundamentos últimos normativos derivados de mandatos divinos. Pero esos recursos no excluyen un control lógico adecuado: los resultados de nuestras intuiciones morales y los mandatos divinos también se definen por sus consecuencias lógicas ${ }^{23}$.

${ }^{22}$ A. Cortina, La moral como forma deficiente del derecho, ibídem, pág. 80. La referencia siguiente es de la pág. 75 .

${ }^{23}$ Cfr. P. L. Quinn, Divine commands and moral requiremems, Oxford, 1978, donde se analizan las diversas consecuencias que lógicamente derivan del análisis de las diversas concepciones referentes a mandamientos divinos y su valor moral. 
Sucede así que mientras la justificación moral del derecho, a través de la idea de legitimidad, es vista, como arriba se apuntó citando a Garzón Valdés, como la correspondencia del derecho con una moral crítica, ahora se ve en el derecho la razón suficiente de una moral sustantiva, pues, «la razón crítica es razón jurídica» ${ }^{24}$. Supongo que Kelsen, quizás, hubiera argumentado que ello es así porque sólo con respecto del derecho se ha desarrollado un conocimiento racional, es decir: científico, sujeto a cánones lógicos explícitos, mientras que el llamado conocimiento moral no reviste hasta la fecha esas características. Con respecto de la moral hay conocimiento práctico, especulación metafísica, análisis metaético, técnicas de socialización o lo que se quiera; sea ello como fuere, lo que no hay es una ciencia constituida de ese objeto impreciso que denominamos «la moral». En estas páginas he querido destacar que buena parte de esa imprecisión resulta de la falta de caracterización precisa de los procedimientos inferenciales lógicos que utilizaría el discurso moral. Las relaciones entre derecho y moral, mientras tanto, permanecen indefinidas, en el sentido literal de la palabra.

Se me ocurre a veces que el cotejo entre normas morales y normas jurídicas se asemeja al afán de encontrar la traducción, en un lenguaje público natural, de las supuestas proposiciones de un lenguaje privado. Y si bien es claro que lo que quizá pensemos con enunciados de un lenguaje privado que nos es exclusivo, necesita manifestarse externamente de alguna suerte para que podamos compartir la creencia, no sólo en la experiencia interna, sino en la verdad de lo que íntimamente creemos, de ninguna manera puede creerse que es factible lograr equivalencia o sinonimia entre lo que nos decimos en nuestro lenguaje interno y lo que públicamente afirmamos cuando expresamos una verdad o una falsedad, una obligación o una prohibición. En nuestros días, la existencia misma de una moral depende de la admisión, desde el vamos, de la autonomía del sujeto, cosa que el derecho considera irrelevante. Pretender fundar moralmente el derecho supone, pues, que la validez del derecho -esto es: su existencia reconocida como normas sociales aplicables- depende del juicio moral de los sujetos morales, juicio moral que, sin embargo, para el mismo derecho objetivo es descartable. Se trata de un ideal nobilísimo: para no violentar la dignidad autónoma de todo individuo, las normas sociales que puedan imponérsele sólo son las asumidas autónomamente por el sujeto obligado, que quien tenga que sufrir una medida social sancionatoria la justifique

${ }^{24}$ A. Cortina, op. cit., pág. 81. 
como un acto propio. Vale decir, lo que es lo mismo, que la llamada voluntad del estado se identifique con la voluntad de cada cual. Este ideal posiblemente no pueda cumplirse y, por lo tanto, las relaciones entre la moral y el derecho nunca puedan especificarse suficientemente, quedando, en casos extremos, a la merced de las ideologías del anarquista, por un lado, y del autócrata, por el otro, el imponer uno u otro orden normativo. 